\title{
Computed Tomography Dose Index Volume
}

National Cancer Institute

\section{Source}

National Cancer Institute. Computed Tomography Dose Index Volume. NCI Thesaurus. Code C101138.

The International Electrotechnical Commission preferred expression of radiation dose in computed tomography (CT) dosimetry. It is calculated by averaging the radiation dose delivered over $\mathrm{x}, \mathrm{y}$ and $\mathrm{z}$ directions and expressed in the SI unit of Gray (Gy). 